\title{
The effect of LOXL2 in hepatocellular carcinoma
}

\author{
LINGHONG WU, YUAN ZHANG，YING ZHU，QINGWEI CONG，YAN XIANG and LINLIN FU \\ Department of Infectious Disease, The First Affiliated Hospital of Dalian Medical University, \\ Dalian, Liaoning 116011, P.R. China
}

Received July 20, 2015; Accepted May 31, 2016

DOI: $10.3892 / \mathrm{mmr} .2016 .5474$

\begin{abstract}
Lysyl oxidase-like 2 (LOXL2) is key in the hepatocellular carcinoma (HCC) tumor microenvironment and metastatic niche formation. However, its effect on proliferation and clinical parameters in HCC require further elucidation. The present study aimed to investigate LOXL2 expression in HCC from in vitro and clinical aspects. The present study constructed LOXL2-small interfering RNA with a lentiviral vector, investigated the effect of LOXL2 on proliferation using HCC cell lines via a series of assays, including reverse transcription-quantitative polymerase chain reaction, cell counting, colony formation, assessment of cell cycle and apoptosis using flow cytometry, MTT and BrdU. Furthermore, 80 tissue samples from HCC patients at The First Affiliated Hospital of Dalian Medical University (Dalian, China) from 2007 to 2010. Immunohistochemical staining was used to clinically verify LOXL2 expression. The results of the present study demonstrate that LOXL2 silencing decreased cell numbers, proliferation, colony formations and cell growth, induced cell cycle arrest and increased apoptosis. Clinically, expression levels of LOXL2 was markedly increased in matched adjacent non-tumor tissue (ANT) samples compared with levels in tumor tissue (TT) samples, and this gradually increased with higher histological grade and more advanced TNM classification in the matched ANT and TT samples. LOXL2 was determined to promote proliferation of $\mathrm{HCC}$ and demonstrated to be highly expressed in HCC ANT samples compared with TT samples.
\end{abstract}

\section{Introduction}

An increased understanding of hepatocellular carcinoma (HCC), which ranks globally as the third or fourth leading cause of cancer-associated mortality (1-3), is key for improving early diagnosis, subsequent patient treatment and prognosis.

Correspondence to: Professor Ying Zhu, Department of Infectious Disease, The First Affiliated Hospital of Dalian Medical University, 222 Zhongshan Road, Xigang, Dalian, Liaoning 116011, P.R. China E-mail: zhuyingsh52@126.com

Key words: hepatocellular carcinoma, LOXL2, si-RNA, proliferation, immunohistochemical staining
HCC has a poor survival rate as it frequently exhibits local invasion and metastasis. A number of clinicopathological factors are important in the treatment of HCC, however, it is also important to develop improved biological indicators for determining therapeutic strategy.

Lysyl oxidase-like 2 (LOXL2) is a member of the lysyl oxidase (LOX) gene family, which includes prototypic LOX and LOX-like (LOXL) proteins, LOXL1, LOXL2, LOXL3 and LOXL4, encoded in mammalian genomes $(4,5)$. The LOX gene family promotes invasion and metastatic niche formation in the skin, aorta, heart, lung, cartilage, kidney, stomach, small intestine, colon, ovaries, testis, and brain of mice $(6,7)$. Furthermore, in previous LOXL2 studies, it was demonstrated that high LOXL2 expression was associated with poor prognosis in colon, esophageal and squamous cell cancers and that LOXL2 was closely associated with tumor invasion and metastasis (8-14). A recent study has reported that LOXL2 is key in tumor microenvironment and metastatic niche formation in HCC with hypoxia-inducible factor $1 \alpha$, transforming growth factor- $\beta$, and microRNAs controlling the expression of LOXL2 (15), however, its effect on proliferation and clinical features require further elucidation.

The present study aimed to directly detect the effects of LOXL2 on the proliferation of HCC cell lines via evaluating the cell apoptosis rate, cell cycle and cell numbers, and verify the association between LOXL2 expression and clinical features in $80 \mathrm{HCC}$ patients. These results lay foundation for future research into $\mathrm{HCC}$.

\section{Materials and methods}

Cell lines. SMMC-7721 and HepG2 human HCC and LO2 human hepatocyte cell lines, were obtained from the Type Culture Collection of the Chinese Academy of Sciences (Shanghai, China). Cells were grown as previously described (16). The cells were maintained as monolayer cultures at $37.8^{\circ} \mathrm{C}$ in a humidified atmosphere of $5 \% \mathrm{CO}_{2}$. All cell lines were cultured in Dulbecco's modified Eagle's medium (Invitrogen; Thermo Fisher Scientific, Inc.) supplemented with $10 \%$ fetal bovine serum (Gibco; Thermo Fisher Scientific, Inc.), $100 \mathrm{U} / \mathrm{ml}$ penicillin and $0.25 \mu \mathrm{g} / \mathrm{ml}$ streptomycin (Hyclone; GE Healthcare Life Sciences, Logan, UT, USA).

Construction of an RNA interference gene with a lentiviral vector. Cells transfected with LOXL2-small interfering RNA 
(LOXL2-siRNA; 5'-ATTACTCCAACAACATCAT-3') using Lipofectamine 2000 (Invitrogen; Thermo Fisher Scientific, Inc.) were used for silencing LOXL2. Cells expressing scrambled short hairpin RNA (shRNA; 5'-TTCTCCGAACGTGTC ACGT-3') in a lentiviral vector served as the control, and a human LOXL2 dsDNA oligonucleotide sequence was synthesized with targeted siRNA sequences by GeneChem Co., Ltd (Shanghai, China). A lentiviral vector, pGCSIL-green fluorescent protein (GFP) plasmid (synthesized by GeneChem Co., Ltd.), was digested by digested by AgeI and EcoRI (GeneChem Co., Ltd.) and connected with the dsDNA sequence and subsequently transformed into competent $E$. coli. Lentiviral vector production and infection were conducted as previously described (17). Stable cell lines expressing LOXL2 shRNAs were selected on lysogeny broth (LB) agar medium after $16 \mathrm{~h}$ culturing at $37^{\circ} \mathrm{C}$ and were identified by polymerase chain reaction (PCR) using a Taq polymerase kit (Takara Bio, Inc., Otsu, Japan). The sense and antisense primers used were as follows: 5'-CCTATTTCCCATGATTCCTTCATA-3' and 5'-GTAATACGGTTATCCACGCG-3'. PCR was conducted at $94^{\circ} \mathrm{C}$ for $30 \mathrm{sec}$, followed by 30 cycles at 94,55 and $72^{\circ} \mathrm{C}$ for $30 \mathrm{sec}$, and $72^{\circ} \mathrm{C}$ for $6 \mathrm{~min}$. The positive clones of recombinant plasmids were sequenced and extracted.

Reverse transcription-quantitative PCR (RT-qPCR). Total RNA was extracted from HCC cells using TRIzol reagent (Invitrogen; Thermo Fisher Scientific, Inc.) according to the manufacturer's protocols. cDNA was obtained by reverse transcription using the Moloney-Murine Leukemia Virus Reverse Transcriptase cDNA Synthesis kit (Promega Corporation, Madison, WI, USA) according to the manufacturer's protocols. Subsequently, mRNA expression levels of the target gene, LOXL2, were detected by qPCR using the SYBR Premix Ex Taq kit (Takara Bio, Inc., Japan). The primer sequences were as follows: Sense, 5'-GTCTGCGGCATGTTTGG-3' and antisense, 5'-GCTCTGGCTTGTACGCTTT-3'; and sense, 5'-TGA CTTCAACAGCGACACCCA-3' and antisense, 5'-CACCCT GTTGCTGTAGCCAAA-3' for GAPDH. The thermocycling conditions were $95^{\circ} \mathrm{C}$ for $15 \mathrm{sec}$, followed by 45 cycles at $95^{\circ} \mathrm{C}$ for $5 \mathrm{sec}$ and $60^{\circ} \mathrm{C}$ for $30 \mathrm{sec}$. Melting curve analysis was conducted to check amplification. Data was calculated using the comparative $2^{-\Delta \Delta \mathrm{Cq}}$ method (18).

Cell counts. HepG2 and SMMC-7721 cells infected with lentiviral vector were seeded at density of $1 \times 10^{3}$ cells/well in 96-well plates and incubated. A Cellomics ${ }^{\mathrm{TM}}$ instrument (ArrayScan VT1; Thermo Fisher Scientific, Inc.) was used to measure the two types of cells stained fluorescent green. The control and LOXL2-siRNA cell numbers were investigated for five days, calculated and analyzed, and a cell growth curve was constructed.

Colony formation assay. Following transfection, the two types of infected cells were seeded at density of $1 \times 10^{3}$ cells/well in 6-well plates and cultured for 14 days. The culture medium was replaced every 3 days. The colonies were rinsed with phosphate-buffered saline (PBS) and fixed with paraformaldehyde for 30-60 min prior to staining with Giemsa for $20 \mathrm{~min}$. Cells were washed a number of times with ddH2O until the plate background was clean and allowed to air dry. Colonies were counted under a microscope (Micropublisher 3.3RTV; Olympus Corporation,

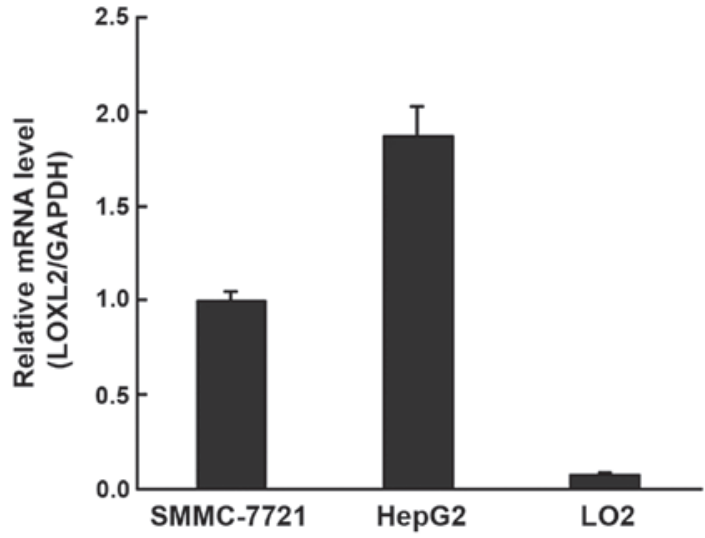

Figure 1. Expression levels of the LOXL2 gene in hepatocellular carcinoma cell lines. LOXL2, lysyl oxidase-like 2.

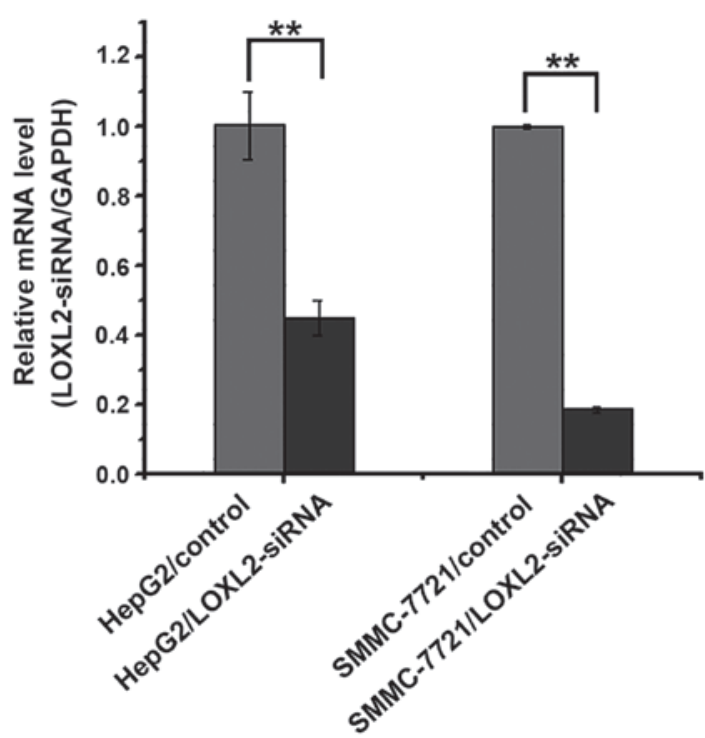

Figure 2. Comparison of LOXL2 mRNA expression levels in hepatocellular carcinoma cell lines treated with LOXL2-siRNA and controls. ${ }^{* *} \mathrm{P}<0.01$ vs. control. LOXL2, lysyl oxidase-like 2; siRNA, small interfering RNA.

Tokyo, Japan). All experiments were conducted in triplicate and data were analyzed using CellQuest Pro software, version 5.1.1.

Flow cytometry to detect the cell cycle. The two types of infected cells were harvested following reaching $\sim 85 \%$ confluence in a 6 -well dish. The cells were centrifuged at $120 \mathrm{x} \mathrm{g}$ for $5 \mathrm{~min}$ at room temperature, the supernatant was discarded, and cells were washed with cold PBS at $4^{\circ} \mathrm{C}$, and centrifuged again under the same conditions prior to collection. The cells were fixed in $70 \%$ ethanol and stored at $4^{\circ} \mathrm{C}$ for $>1 \mathrm{~h}$. The cells were centrifuged at $120 \mathrm{x} \mathrm{g}$ for $5 \mathrm{~min}$ at room temperature and washed again prior to addition of staining solution (propidium iodide) and the cells were subsequently resuspended. The cell cycle was analyzed with flow cytometry (FACSCalibur; BD Biosciences, Franklin Lakes, NJ, USA) and CellQuest Pro software, version 5.1.1. All experiments were performed in triplicate.

Flow cytometry to detect apoptosis. The cells were harvested, washed with D-Hanks (Haling Biotechnology Co., Ltd., Shanghai, China), trypsinized, centrifuged at $150 \mathrm{x}$ g for $5 \mathrm{~min}$ 
A
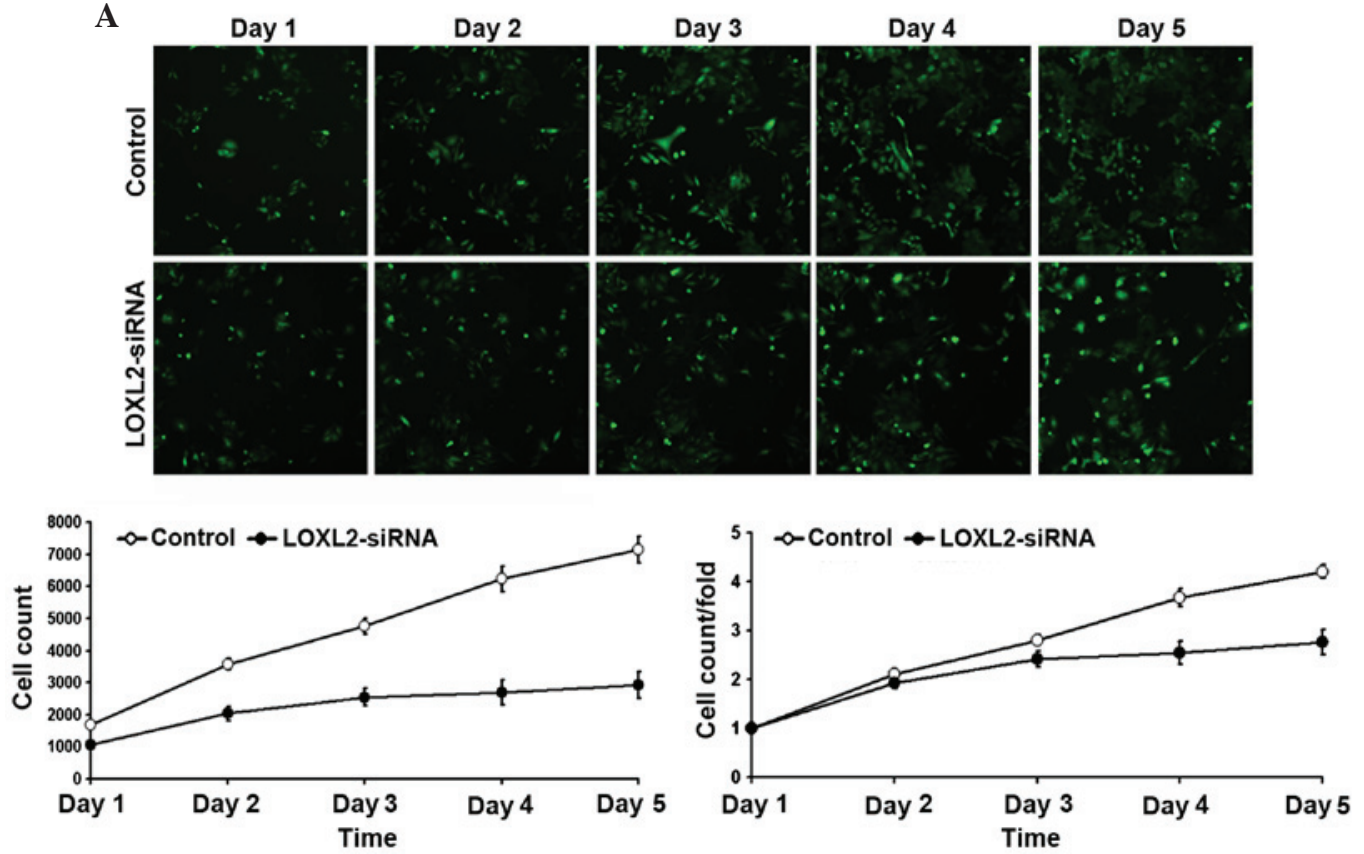

B

Day 1
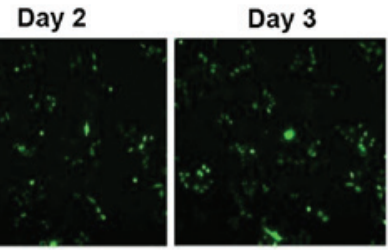

Day 4

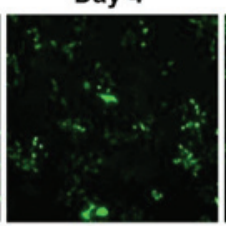

Day 5
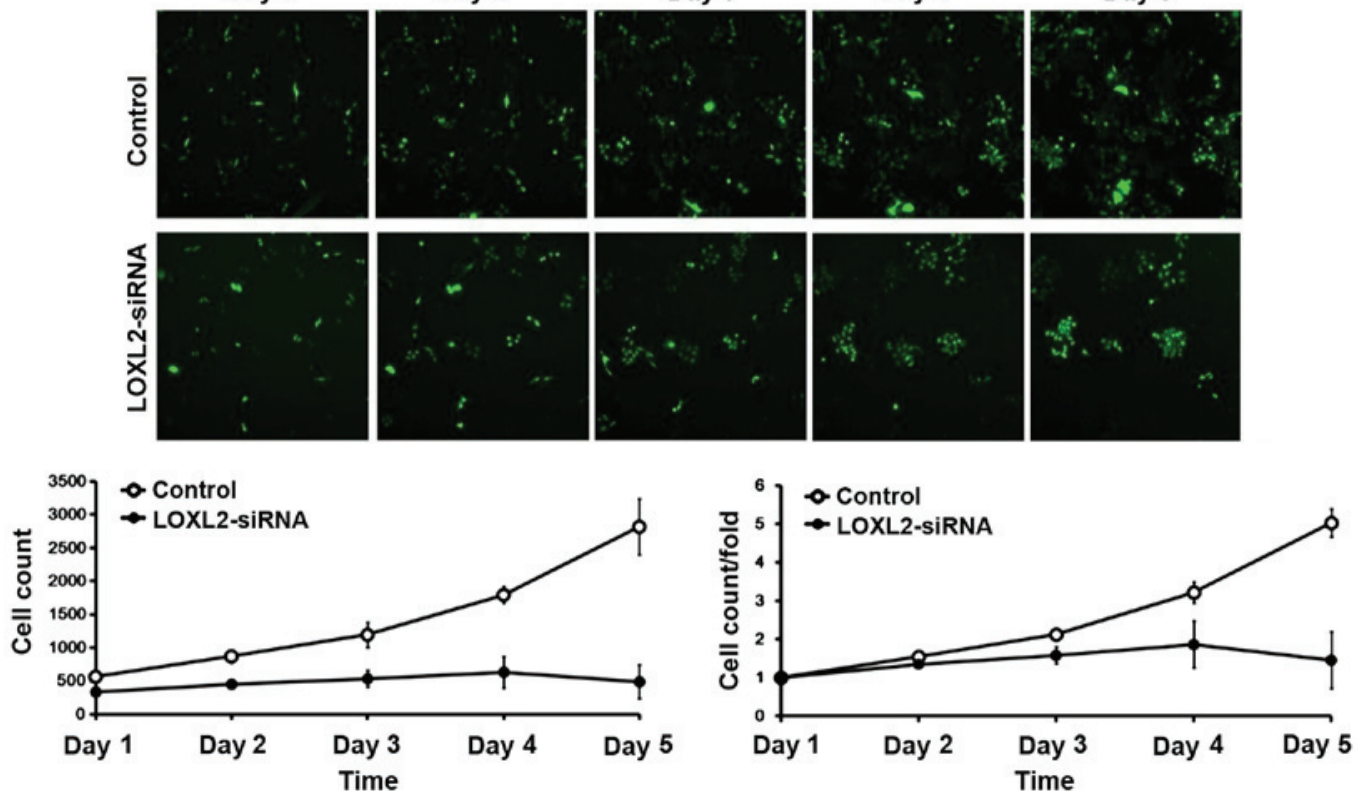

Figure 3. LOXL2 silencing decreased proliferation of hepatocellular carcinoma cells. (A) The number of cells and fold change in proliferation in HepG2 cells. (B) The number of cells and fold increase in proliferation in SMMC-7721 cells. LOXL2, lysyl oxidase-like 2; siRNA, small interfering RNA.

at room temperature, and the supernatant was then discarded. The precipitated cells were washed once with PBS, centrifuged under the same conditions, and then collected following washing with binding buffer. The cell suspension was gathered with a final density of $1 \times 10^{6}-1 \times 10^{7}$ cells $/ \mathrm{ml}$ and $5 \mu$ l Annexin V Apoptosis Detection kit APC (eBioscience, Inc., San Diego, CA, USA) was added for 10-15 min in a dark room at room temperature. Flow cytometry analysis was then conducted using FACSCalibur. All experiments were carried out in triplicate.

MTT assay and BrdU labeling. Cells from the two infected cell lines were seeded in 96-well plates at an initial density of $2 \times 10^{4} /$ well. HepG 2 cells were stained every $24 \mathrm{~h}$ with $10 \mu 1$ sterile MTT (5 mg/ml; Beijing Dingguo Changsheng
Biotechnology Co., Ltd.) for $4 \mathrm{~h}$ at $37^{\circ} \mathrm{C}$. The culture medium was removed, and $100 \mathrm{ml}$ of dimethyl sulfoxide (Sigma-Aldrich) was added to stop the reaction. SMMC-7721 cells were incubated with BrdU reagent [10 $\mu \mathrm{l} /$ well; Cell Proliferation ELISA, BrdU (colorimetric); Roche Diagnostics, Basel, Switzerland] and fixed, and the stationary liquid was discarded. Substrate solution was added to finish the reaction following staining with anti-BrdU antibodies for $90 \mathrm{~min}$ at room temperature. HepG2 cells were detected at 5 days, and SMMC-7721 cells were detected at 24 and $96 \mathrm{~h}$. The absorbance was measured at a wavelength of $490 \mathrm{~nm}$ for the MTT assay on HepG2 cells and a wavelength of $450 \mathrm{~nm}$ for the BrdU assay on SMMC-7721 cells with a microplate reader. All experiments were conducted in triplicate. The fold change in proliferation 
A
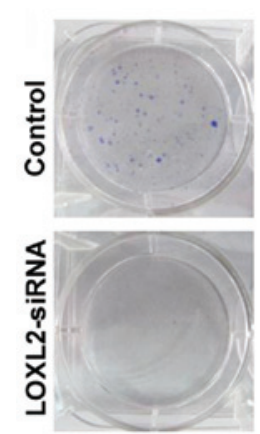

C

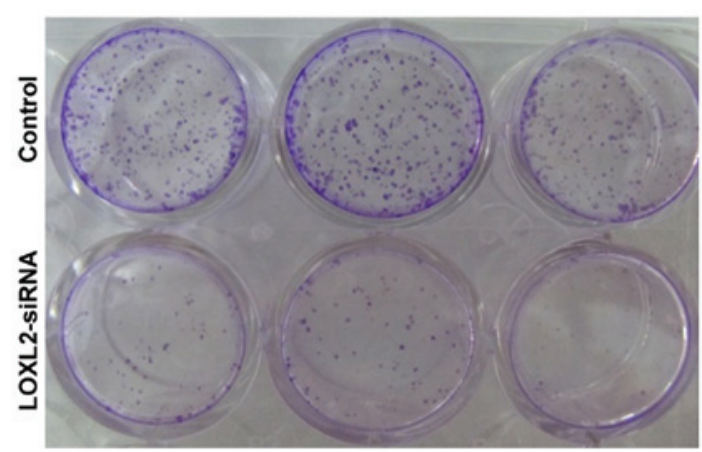

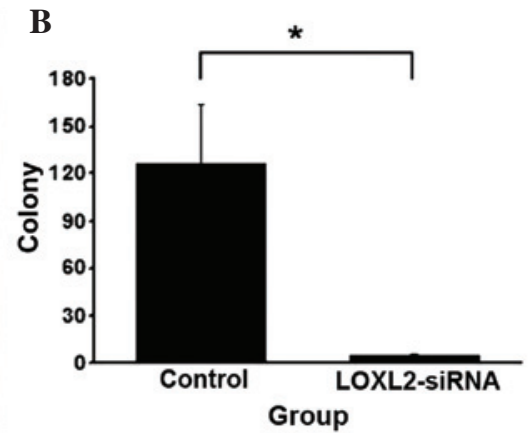

D

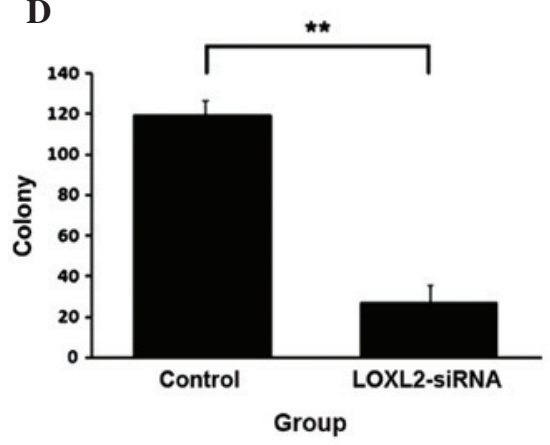

Figure 4. Effects of LOXL2 silencing on hepatocellular carcinoma cell colony formation. (A) Representative images of the colony formation assay and (B) quantification of colony formation efficiency in HepG2 cells. (C) Representative images of the colony formation assay and (D) quantification of colony formation efficiency in SMMC-7721 cells. ; $\mathrm{P}<0.05,{ }^{* *} \mathrm{P}<0.01$ vs. the control group. LOXL2, lysyl oxidase-like 2; siRNA, small interfering RNA.

A

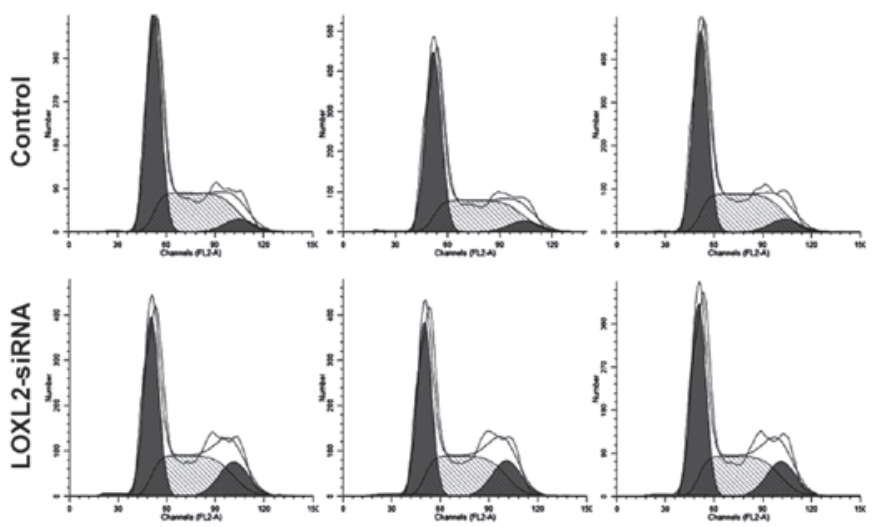

C

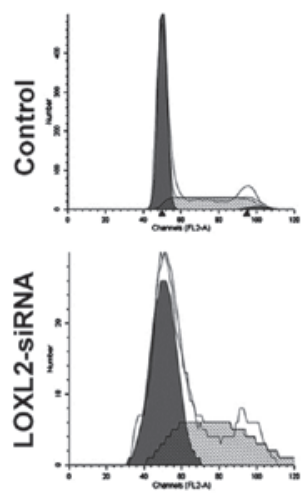

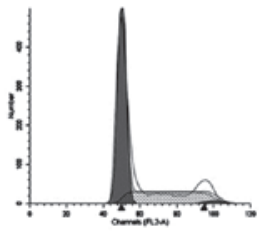

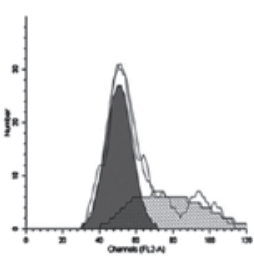

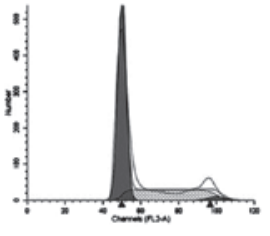

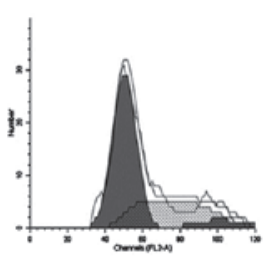

B

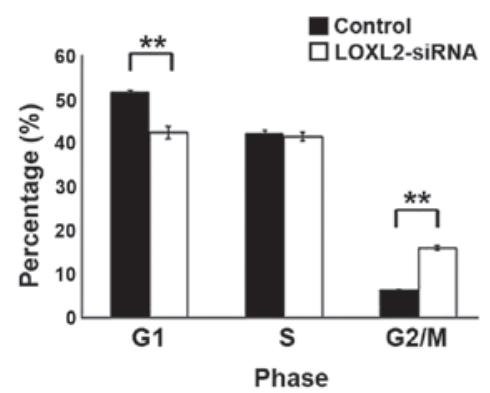

D

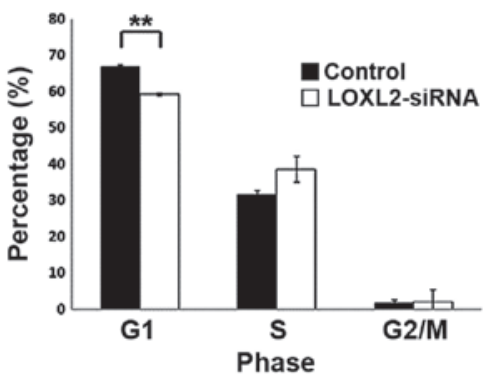

Figure 5. Effects of LOXL2 silencing on hepatocellular carcinoma cell cycle distributions. (A) Representative histograms of flow cytometry and (B) histogram of percentage of different cell cycle phases in HepG2 cells. (C) Representative histograms of flow cytometry and (D) histogram of percentages of different cell cycle phases in SMMC-7721 cells. ** P<0.01 vs. the control group. LOXL2, lysyl oxidase-like 2; siRNA, small interfering RNA.

of different groups were calculated, analyzed, and presented in figures.
HCC patients and tissue specimens. A total of 80 samples were collected from patients (68 males and 12 females; median 
A
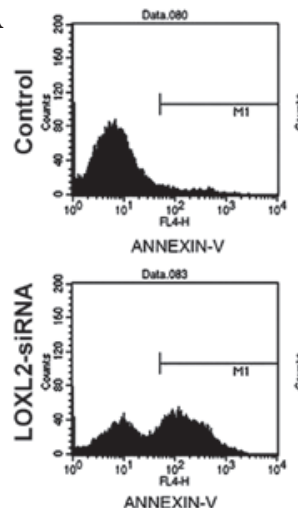

C
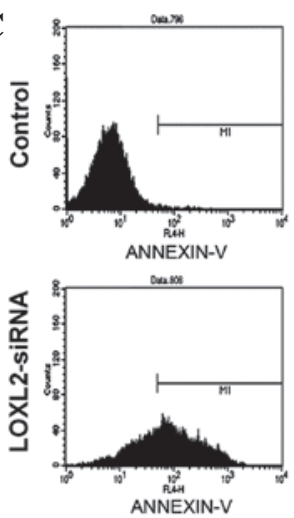
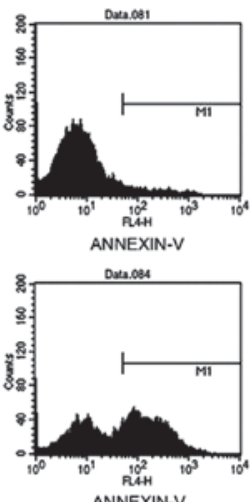

awn
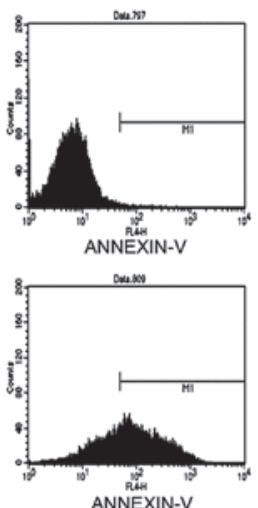
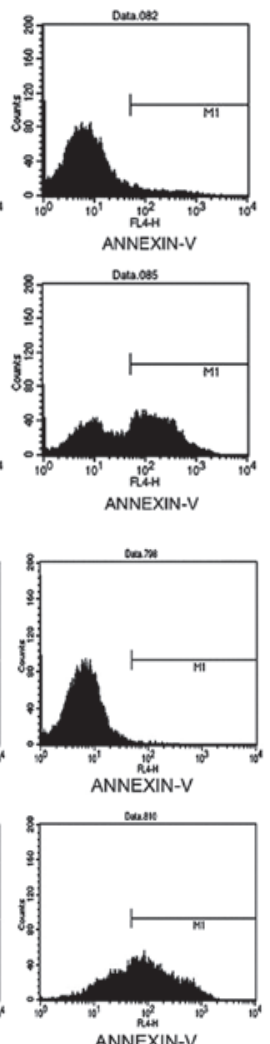
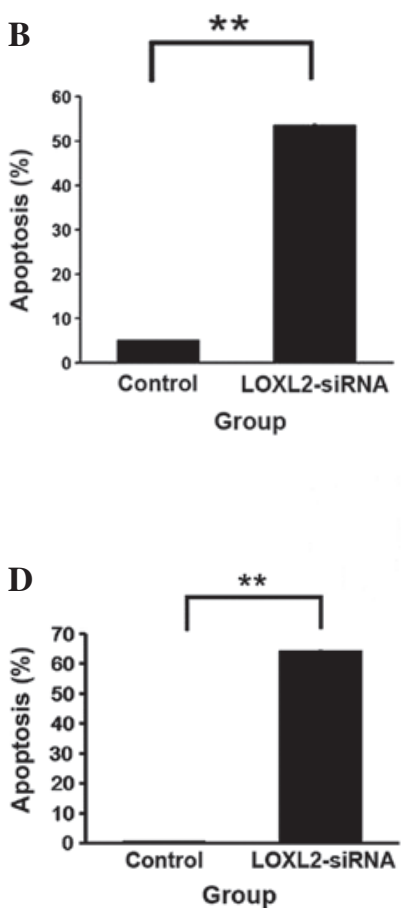

Figure 6. Effects of LOXL2 silencing on hepatocellular carcinoma cell apoptosis. (A) Representative histograms of flow cytometry and (B) apoptosis rates in the HepG2 cell line. (C) Representative histograms of flow cytometry and (D) apoptosis rates in the SMMC-7721 cell line. ${ }^{* *} \mathrm{P}<0.01$ vs. the control group. LOXL2, lysyl oxidase-like 2; siRNA, small interfering RNA.

A

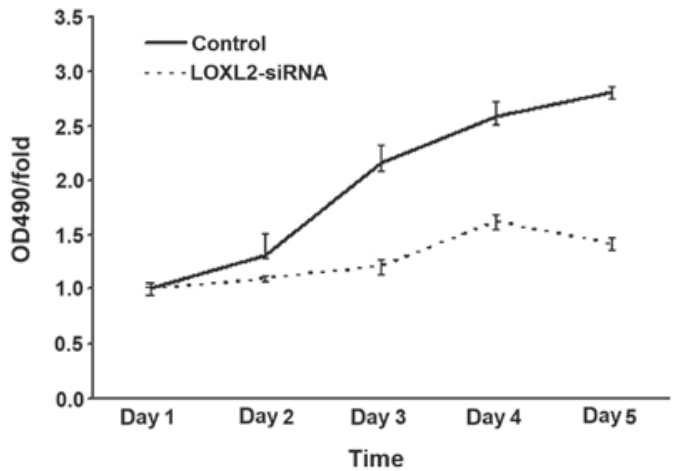

B

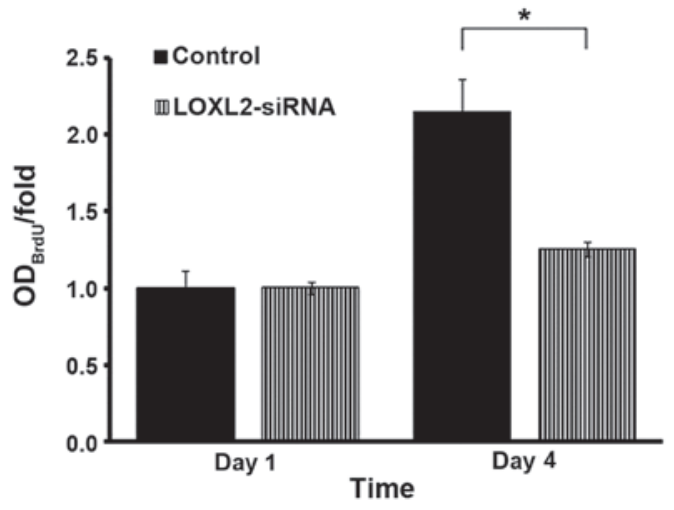

Figure 7. Effects of LOXL2 silencing on hepatocellular carcinoma cell absorbance. (A) MTT assays were performed on the indicated days to determine the absorbance of HepG2 cells. (B) BrdU labeling was performed on the indicated days to demonstrate the absorbance of SMMC-7721 cells. ${ }^{*} \mathrm{P}<0.05$ vs. the control group. LOXL2, lysyl oxidase-like 2 , siRNA, small interferingRNA; OD, optical density. age, 51; age range, 26-72) at The First Affiliated Hospital of Dalian Medical University (Dalian, China) from 2010 to 2014. Tumor tissue (TT) and adjacent non-tumor tissue (ANT) were resected by surgical excision. Clinicopathological data were obtained from archived medical records. The records included patient gender, age, size of tumor, vascular invasion, tumor number, liver cirrhosis, Child-Pugh grade, hepatitis B surface antigen (HBsAg), $\alpha$-fetoprotein (AFP), histological grade, and pathological stage. The liver cirrhosis was diagnosed by pathology, and the Child-Pugh grade was divided into three grades according to evaluation indexes, including hepatic encephalopathy, ascites, bilirubin, albumin and prothrombin time. Serum HBsAg was detected using ARCHITECT HBsAg (Abbott Laboratories, Chicago, IL, USA) and AFP was determined using Elecsys and Cobas analyzers (Roche Diagnostics). The histological grade was determined according to Edmondson-Steiner modification, and pathological staging was determined according to the seventh edition of the tumor node metastasis (TNM) classification of the International Union Against Cancer (19). Patient consent and approval from the Institutional Research Ethics Committee were obtained prior to the use of these clinical materials for research purposes.

Immunohistochemistry analysis. Two tissue microarrays were constructed containing 80 liver TT and ANT samples. Cores of $1.5 \mathrm{~mm}$ in diameter were sampled from each specimen ( 2 cores/specimen), and were fixed with $10 \%$ formalin and embedded in paraffin in the microarray. The immunohistochemical (IHC) procedure was conducted as previously 
Table I. Clinical information regarding hepatocellular carcinoma samples.

\begin{tabular}{|c|c|}
\hline Characteristic & $\begin{array}{c}\text { Number of } \\
\text { cases }(\%)\end{array}$ \\
\hline Total & $80(100)$ \\
\hline \multicolumn{2}{|l|}{ Gender } \\
\hline Male & $68(85)$ \\
\hline Female & $12(15)$ \\
\hline \multicolumn{2}{|l|}{ Age (years) } \\
\hline$<50$ & $34(42.5)$ \\
\hline$\geq 50$ & $46(57.5)$ \\
\hline \multicolumn{2}{|l|}{ Size (cm) } \\
\hline$\leq 2$, no invasion & $0(0)$ \\
\hline$\leq 5$, or 3 nodules, $\leq 3$; no invasion & $11(13.75)$ \\
\hline$>5$, or multiple nodules & $15(18.75)$ \\
\hline Vascular invasion & $54(67.5)$ \\
\hline \multicolumn{2}{|l|}{ Vascular invasion } \\
\hline Negative & $26(32.5)$ \\
\hline Position & $54(67.5)$ \\
\hline \multicolumn{2}{|l|}{ Number of tumors } \\
\hline 1 & $62(77.5)$ \\
\hline$\geq 2$ & $18(22.5)$ \\
\hline \multicolumn{2}{|l|}{ Liver cirrhosis } \\
\hline Negative & $6(7.5)$ \\
\hline Positive & $74(92.5)$ \\
\hline \multicolumn{2}{|l|}{ Child-Pugh grade } \\
\hline A & $74(92.5)$ \\
\hline $\mathrm{B}$ & $6(7.5)$ \\
\hline $\mathrm{C}$ & $0(0)$ \\
\hline \multicolumn{2}{|l|}{ HBsAg } \\
\hline Negative & $21(26.25)$ \\
\hline Positive & $59(73.75)$ \\
\hline \multicolumn{2}{|l|}{$\mathrm{AFP}(\mathrm{ng} / \mathrm{ml})$} \\
\hline$\leq 20$ & $29(36.25)$ \\
\hline$>20$ & $51(63.75)$ \\
\hline \multicolumn{2}{|l|}{ Tumor histological grade } \\
\hline I & $3(3.75)$ \\
\hline I-II & $8(10)$ \\
\hline II & $44(55)$ \\
\hline II-III & $7(8.75)$ \\
\hline III & $18(22.5)$ \\
\hline \multicolumn{2}{|l|}{ TNM classification } \\
\hline 1 (TINOM0) & $25(31.25)$ \\
\hline 2 (T2NOM0) & $34(42.5)$ \\
\hline 3 (T2N1M0 or T3N0M0) & $21(25)$ \\
\hline
\end{tabular}

HBsAg, hepatitis B surface antigen; AFP, alpha fetal protein; TNM, tumor node metastasis.

described (20). The sections were treated with the following primary antibody overnight at $4^{\circ} \mathrm{C}$ : Monoclonal rabbit
A

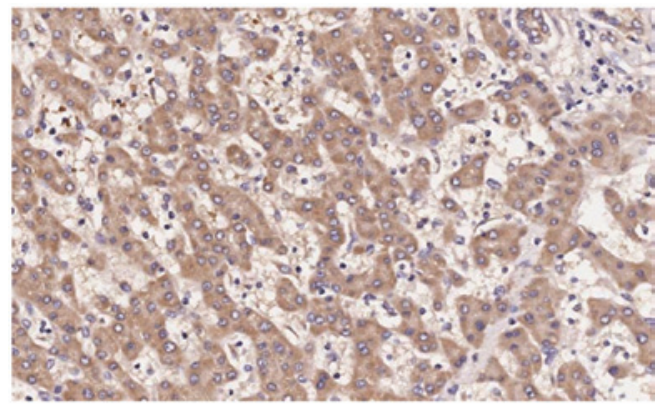

B

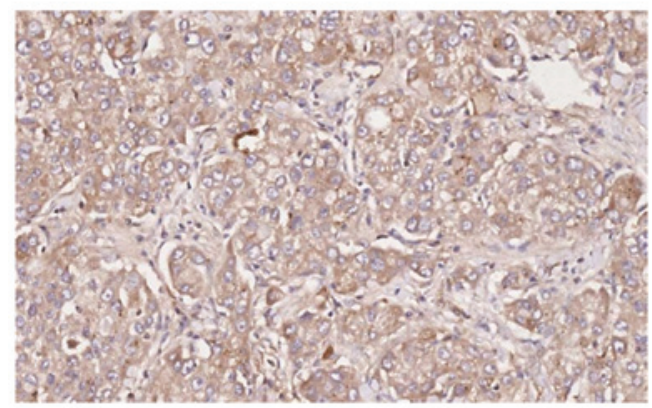

C

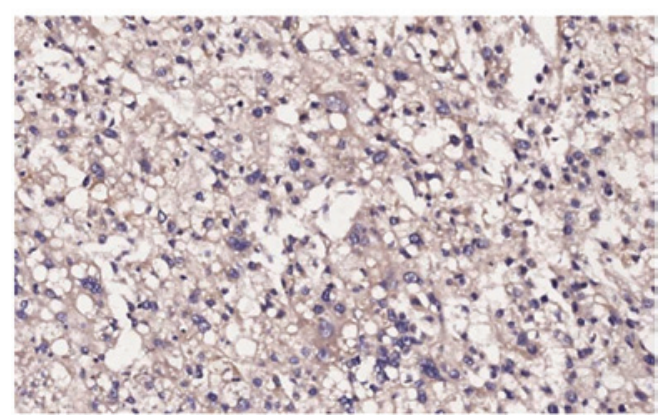

Figure 8. Immunohistochemical staining of lysyl oxidase-like 2 in hepatocellular carcinoma tissue. (A) Matched adjacent non-tumor tissue; (B) tumor tissue; (C) normal liver tissue (magnification, x200).

anti-human LOXL2 antibody (1:100; cat. no. ab179810; Abcam, Cambridge, MA, USA). All the sections were incubated for $30 \mathrm{~min}$ at $37^{\circ} \mathrm{C}$ with peroxidase-labeled goat anti-rabbit secondary antibody with diaminobenzidine as a chromogen (1:1,000; cat. no. M080825; Beijing Zhongshan Golden Bridge Biotechnology Co., Ltd., Beijing China). The sections were stained with hematoxylin. IHC staining was quantitatively analyzed with Image Pro Plus 6.0 (Media Cybernetics, Inc., Rockville, MD, USA) computerized image analysis system using the automatic measurement program. The stained sections were analyzed to verify the mean integral optical density (IOD), which represented the strength of staining signals as measured per positive pixel.

Statistical analysis. All data are expressed as the mean \pm standard deviation. The intergroup difference was compared using an independent samples t-test. These analyses were conducted using SPSS 19.0 software (SPSS, Inc., Chicago, IL, USA). P<0.05 was considered to indicate a statistically significant difference.

\section{Results}

LOXL2 was highly expressed in HCC cell lines. RT-qPCR demonstrated that LOXL2 mRNA expression levels were 
Table II. Expression of lysyl oxidase-like 2 in ANT and TT of hepatocellular carcinoma patients.

\begin{tabular}{|c|c|c|c|}
\hline \multirow[b]{2}{*}{ Characteristic } & \multicolumn{2}{|c|}{ IOD of LOXL2 expression $\left(\mathrm{D} / \mu \mathrm{m}^{2}, \mathrm{X} \pm \mathrm{SD}\right)$} & \multirow{2}{*}{$\begin{array}{c}\text { P-value } \\
\text { (TT vs. ANT) }\end{array}$} \\
\hline & ANT & TT & \\
\hline \multicolumn{4}{|l|}{ Gender } \\
\hline Male & $62079.73 \pm 26373.13$ & $36455.52 \pm 20406.78$ & $<0.0001^{\mathrm{b}}$ \\
\hline Female & $60380.53 \pm 25146.45$ & $44101.86 \pm 28961.48$ & 0.365 \\
\hline \multicolumn{4}{|l|}{ Age (years) } \\
\hline$<50$ & $70898.34 \pm 26281.21$ & $38834.03 \pm 22720.20$ & $0.003^{\mathrm{b}}$ \\
\hline$\geq 50$ & $55393.36 \pm 24145.98$ & $36737.76 \pm 2146.00$ & $<0.0001^{\mathrm{b}}$ \\
\hline \multicolumn{4}{|l|}{ Vascular invasion } \\
\hline Negative & $58405.79 \pm 28093.89$ & $37583.48 \pm 22365.60$ & $0.005^{\mathrm{b}}$ \\
\hline Positive & $63486.61 \pm 25120.36$ & $37611.61 \pm 21813.34$ & $<0.0001^{\mathrm{b}}$ \\
\hline \multicolumn{4}{|l|}{ Tumor size $(\mathrm{cm})$} \\
\hline Single $\leq 5,3$ nodules $\leq 3$, and no invasion & $62813.08 \pm 30431.63$ & $32362.90 \pm 18411.26$ & 0.117 \\
\hline Single $>5$, or multiple nodules & $54942.92 \pm 26746.69$ & $41411.91 \pm 24779.17$ & 0.101 \\
\hline Vascular invasion & $63486.61 \pm 25120.36$ & $37611.61 \pm 21852.23$ & 0.110 \\
\hline \multicolumn{4}{|l|}{ Number of tumors } \\
\hline 1 & $61491.61 \pm 27278.68$ & $37091.56 \pm 21566.21$ & $<0.0001^{\mathrm{b}}$ \\
\hline$\geq 2$ & $63055.97 \pm 21830.35$ & $39362.26 \pm 23365.34$ & $0.011^{\mathrm{a}}$ \\
\hline \multicolumn{4}{|l|}{ Child-Pugh grade } \\
\hline A & $62751.23 \pm 24479.83$ & $37348.61 \pm 21706.92$ & $<0.0001^{\mathrm{b}}$ \\
\hline B & $51018.5115 \pm 42073.69$ & $40733.37 \pm 25548.37$ & 0.412 \\
\hline \multicolumn{4}{|l|}{ HBsAg } \\
\hline Negative & $60973.84 \pm 24476.70$ & $38580.76 \pm 19154.65$ & $<0.0001^{\mathrm{b}}$ \\
\hline Positive & $62160.67 \pm 26818.31$ & $37254.26 \pm 22878.54$ & $<0.0001^{\mathrm{b}}$ \\
\hline \multicolumn{4}{|l|}{ Liver cirrhosis } \\
\hline Negative & $57683.43 \pm 19908.48$ & $37838.50 \pm 21361.29$ & 0.304 \\
\hline Positive & $62188.00 \pm 26583.26$ & $34691.35 \pm 29525.76$ & $<0.0001^{\mathrm{b}}$ \\
\hline \multicolumn{4}{|l|}{$\mathrm{AFP}(\mathrm{ng} / \mathrm{ml})$} \\
\hline$\leq 20$ & $59293.34 \pm 30001.59$ & $35868.95 \pm 17343.50$ & $0.005^{\mathrm{b}}$ \\
\hline$>20$ & $6329.51 \pm 23705.50$ & $38588.19 \pm 24151.63$ & $<0.0001^{\mathrm{b}}$ \\
\hline \multicolumn{4}{|l|}{ Histological grade } \\
\hline I & $26391.16 \pm 18678.73$ & $25509.08 \pm 7018.12$ & 0.887 \\
\hline I-II & $46181.98 \pm 26941.30$ & $30407.17 \pm 17293.95$ & 0.217 \\
\hline II & $65032.08 \pm 24868.29$ & $43165.85 \pm 24588.47$ & $<0.0001^{\mathrm{b}}$ \\
\hline II-III & $58476.11 \pm 33510.37$ & $43891.44 \pm 13002.07$ & 0.304 \\
\hline III & $67242.60 \pm 22814.09$ & $27042.97 \pm 15674.68$ & $<0.0001^{\mathrm{b}}$ \\
\hline \multicolumn{4}{|l|}{ TNM classification } \\
\hline 1 (TINOM0) & $58089.55 \pm 28652.64$ & $36475.76 \pm 22086.88$ & $0.005^{\mathrm{b}}$ \\
\hline 2 (T2N0M0) & $61571.45 \pm 24221.65$ & $37021.99 \pm 22073.14$ & $<0.0001^{\mathrm{b}}$ \\
\hline 3 (T2N1M0, T3N0M0) & $67045.77 \pm 26313.12$ & $39883.61 \pm 22119.33$ & $0.001^{\mathrm{b}}$ \\
\hline
\end{tabular}

${ }^{\mathrm{a}} \mathrm{P}<0.05,{ }^{\mathrm{b}} \mathrm{P}<0.01$, TT compared with ANT. TT, tumor tissue; ANT, adjacent non-tumor tissue; IOD, integral optical density; HBsAg, hepatitis B surface antigen; AFP, alpha fetal protein; TNM, tumor node metastasis.

markedly upregulated in HepG2 and SMMC-7721 cells (Fig. 1). Subsequently, when the two cell lines were infected with LOXL2-siRNA, the RT-qPCR results indicated that the expression of LOXL2 mRNA was significantly decreased in HepG2 $(\mathrm{P}=0.00310)$ and SMMC-7721 cell lines $(\mathrm{P}<0.0001)$ (Fig. 2).
LOXL2 silencing inhibited HepG2 and SMCC-7721 cell proliferation. As presented in Fig. 3, following LOXL2 gene silencing, the number of cells and the fold change in proliferation were markedly reduced in the HepG2 (Fig. 3A) and SMMS-7721 (Fig. 3B) cells. These results indicated that the silencing of LOXL2 was associated with cell proliferation. 


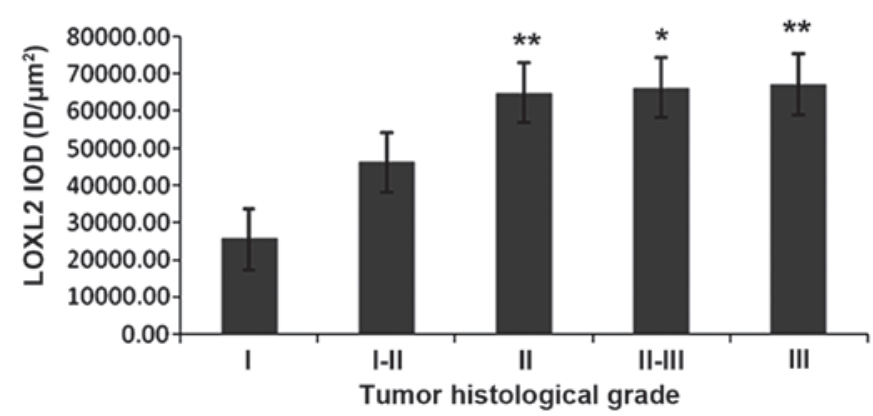

Figure 9. Changes to LOXL2 expression levels in adjacent non-tumor tissues with different tumor histological grades. ${ }^{*} \mathrm{P}<0.05,{ }^{* * *} \mathrm{P}<0.01$ vs. grade I samples. LOXL2, lysyl oxidase-like 2; IOD, integral optical density.

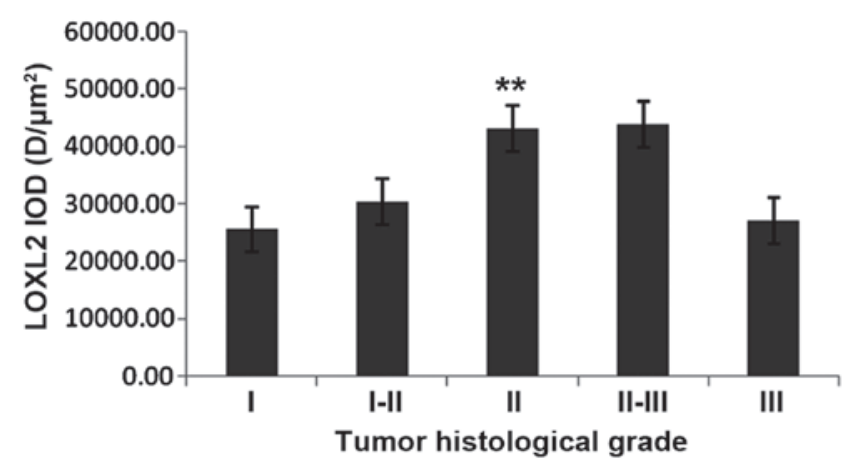

Figure 10. Changes to LOXL2 expression levels in tumor tissue with different tumor histological grades. "* $\mathrm{P}<0.01$ vs. grade I samples. LOXL2, lysyl oxidase-like 2; IOD, integral optical density.

LOXL2 silencing reduced HepG2 and SMMC-7721 cell colony formation. The effect of LOXL2 silencing on growth and colony numbers in HCC cell lines is presented in Fig. 4. LOXL2 silencing reduced the anchorage-independent growth ability of HepG2 (Fig. 4A) and SMMC-7721 cells (Fig. 4C) in soft agar. Cell clone numbers were significantly decreased in HepG2 (P=0.0287; Fig. 4B) and SMMC-7721 cells $(\mathrm{P}=0.00022$; Fig. 4D), which were infected with LOXL2-siRNA.

LOXL2 silencing induced cycle arrest in HepG2 and $S M M C-7721$ cells. LOXL2 silencing significantly decreased the fraction of $\mathrm{G}_{1}$ phase cells in HepG2 ( $\mathrm{P}=0.002$; Fig. $5 \mathrm{~A}$ and $\mathrm{B}$ ) and SMMC-7721 cells $(\mathrm{P}=<0.0001$; Fig. $5 \mathrm{C}$ and $\mathrm{D})$ compared with the controls. In addition, LOXL2 silencing significantly increased the percentage of $\mathrm{G}_{2} / \mathrm{M}$ phase cells in HepG2 $(\mathrm{P}<0.0001$; Fig. 5A and $\mathrm{B})$ and markedly decreased the number of cells in S-phase in SMMC-7721 cells $(\mathrm{P}=0.06$; Fig. $5 \mathrm{C}$ and $\mathrm{D}$ ). These results suggested that LOXL2 contributed to the cell phase transition of HCC cells, particularly the $\mathrm{G}_{1}$ phase.

LOXL2 silencing accelerated apoptosis in HepG2 and SMMC-7721 cells. Following LOXL2 silencing, the percentage of apoptotic cells was increased in HepG2 $(\mathrm{P}<0.0001$; Fig. 6A and B) and SMMC-7721 cells $(\mathrm{P}<0.0001$; Fig. $6 \mathrm{C}$ and $\mathrm{D})$ compared with the controls. The results indicated that LOXL2 silencing increased apoptosis in HCC cells.

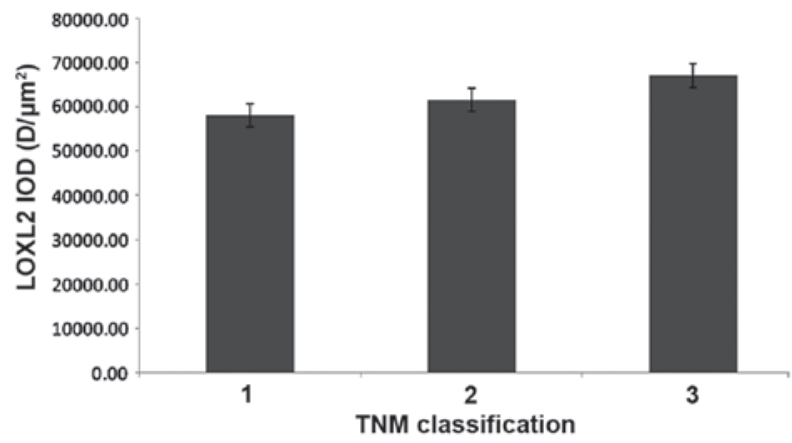

Figure 11. Changes to LOXL2 expression levels in adjacent non-tumor tissues with different TNM classification. LOXL2, lysyl oxidase-like 2; TNM, tumor node metastasis; IOD, integral optical density.

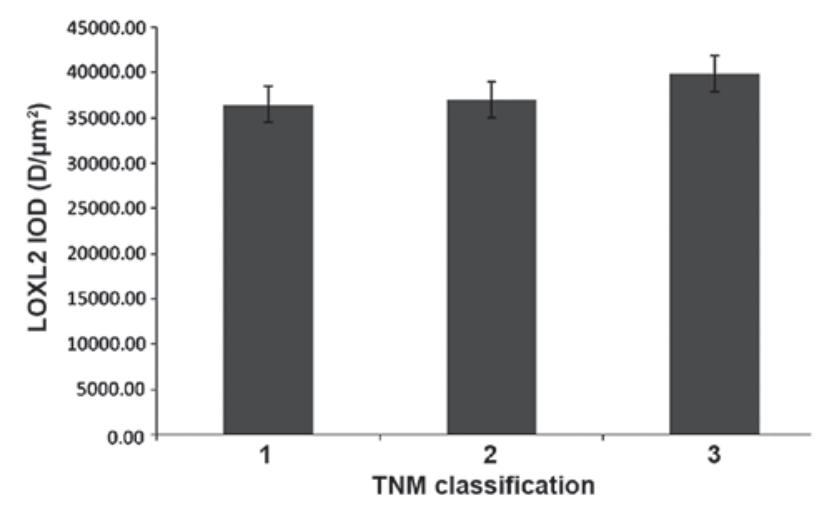

Figure 12. Changes to LOXL2 expression levels in tumor tissue with different TNM classification. LOXL2, lysyl oxidase-like 2; TNM, tumor node metastasis; IOD, integral optical density.

LOXL2 silencing suppressed HepG2 and SMMC-7721 cell growth as analyzed by MTT and BrdU. MTT assays were used to detect the absorbance of infected HepG2 cells. LOXL2 silencing decreased the growth of HepG2 cells over five days culture (Fig. 7A). Similarly, BrdU labeling was used in SMMC-7721 cells due to thymine replacement competition in the $\mathrm{S}$ phase, and it was observed that LOXL2 silencing also decreased the growth of SMMC-7721 cells on day $4(\mathrm{P}=0.0151$; Fig. 7B). These results demonstrated that LOXL2 is important in suppressing the growth of HCC cells in vitro.

Characteristics of the HCC patients. Tumor size of the $80 \mathrm{HCC}$ patients ranged from $2.2-12.5 \mathrm{~cm}$ (mean, $7.35 \mathrm{~cm}$ ). The characteristics of all the tissue samples are summarized in Table I.

Protein location of LOXL2 in HCC tissue samples. Expression of LOXL2 was detected in matched ANT and TT samples by IHC staining, LOXL2 staining was detected in the cytoplasm, using normal liver tissue as a control (Fig. 8).

Association of LOXL2 expression with clinicopathological factors. Characteristics of the $80 \mathrm{HCC}$ patients were compared. Using horizontal comparative research, LOXL2 expression was demonstrated to be higher in ANT samples than in TT samples, and a statistical significance was indicated for the majority of clinicopathological factors, including gender, age, vascular invasion, tumor number, Child-Pugh grade A, HbsAg, 
liver cirrhosis positive and AFP ( $\mathrm{P}<0.05$; Table II). Vertical comparison in ANT and TT samples indicated no significant association was observed between LOXL2 expression levels and all the clinicopathological factors, except histological grade ( $\mathrm{P}>0.05$, data not shown).

LOXL2 expression levels were altered in different histological grades. IHC staining of HCC samples indicated that the protein expression level of LOXL2 was increased in matched ANT compared with TT in grade II $(\mathrm{P}=<0.0001)$ and grade III $(\mathrm{P}=<0.0001)$ subgroup patients (Table II). In matched ANT samples, the expression levels of LOXL2 was increased with the tumor histological grade, LOXL2 expression was higher in grade II than in grade $\mathrm{I}(\mathrm{P}=0.003)$ and it was gradually increased in grade II-III $(\mathrm{P}<0.05)$ and grade III $(\mathrm{P}<0.01)$ subgroup patients (Fig. 9). In TT samples, the expression increased to grade II $(\mathrm{P}<0.01)$, while it decreased in grade III with no marked difference between grade II-III and III ( $\mathrm{P}=0.076$; Fig. 10).

LOXL2 expression differed with TNM classification. In HCC samples, the protein expression of LOXL2 in ANT samples was increased compared with TT in TNM classification 1 $(\mathrm{P}=0.005)$, classification $2(\mathrm{P}=<0.0001)$ and classification 3 $(\mathrm{P}=0.001)$. In addition, LOXL2 expression was gradually increased with more advanced TNM classification in matched ANT and TT (Table II), but there were no significant differences observed in the ANT or TT samples (Figs. 11 and 12).

\section{Discussion}

In the present study, the mRNA expression levels of LOXL2 were decreased in the two cell lines infected with siRNA lentiviral vector, and the cell numbers, proliferation and anchorage-independent growth ability were significantly decreased. In addition, the rate of cell apoptosis increased. The results of the current study provide novel evidence that silencing LOXL2 may decrease the proliferation of HCC cells in vitro. Furthermore, in the cell cycle distribution, LOXL2 silencing notably decreased the fraction of $G_{1}$ phase cells in HepG2 and SMMC-7721 cells and increased the fraction of $\mathrm{G}_{2} / \mathrm{M}$ phase cells in HepG2 cells and $\mathrm{S}$-phase cells in SMMC-7721 cells. This indicates that LOXL2 contributes to HCC cell growth in the $G_{1}$ phase as when the expression is reduced, HCC growth may be blocked. This may be beneficial in novel therapeutic strategies for HCC patients in the future.

Wong et al (15) demonstrated that LOXL2 was overexpressed in human HCC. The present study of HCC patients further demonstrated that LOXL2 was positively expressed in the cytoplasm and that the expression of LOXL2 in matched ANT samples was markedly increased compared with TT samples. Furthermore, LOXL2 expression increased with histological grade and more advanced TNM classification. The results of the present study were consistent with recent reports. The tumor-stroma crosstalk has been demonstrated to be important in tumor progression. Increased LOXL2 expression resulted in tumor progression and metastasis, likely by promoting tumor cell invasion and remodeling of the tumor microenvironment (21-25). It has been demonstrated that LOXL2 mediates induction of epithelial-mesenchymal transition and matrix remodeling enzymes to modify the tumor microenvironment, thus, promoting survival and proliferation of the tumor cells (26-29). These results contribute to improved understanding of the association between LOXL2 expression levels and clinicopathological factors in $\mathrm{HCC}$.

In conclusion, LOXL2 promotes HCC proliferation and is highly expressed in ANT samples compared with TT samples. These results aid improved understanding of the importance of LOXL2 in HCC, laying foundation for future research. Furthermore, additional in vitro and clinical studies are required to fully understand the role of LOXL2 in HCC.

\section{Acknowledgements}

The authors would like to thank GeneChem Co., Ltd. (Shanghai, China) for construction of the lentiviral vector and synthesis of the pGCSIL-GFP plasmid. The present study was supported by the National Natural Science Foundation of China (grant no. 81273925).

\section{References}

1. Schütte K, Bornschein J and Malfertheiner P: Hepatocellular carcinoma-epidemiological trends and risk factors. Dig Dis 27: 80-92, 2009.

2. Abrams P and Marsh JW: Current approach to hepatocellular carcinoma. Surg Clin North Am 90: 803-816, 2010.

3. Lin CL and Kao JH: Optimal management of hepatocellular carcinoma: Challenges and opportunities. J Gastroenterol Hepatol 25: 1336-1338, 2010.

4. Cano A, Santamaría PG and Moreno-Bueno G: LOXL2 in epithelial cell plasticity and tumor progression. Future Oncol 8: 1095-1108, 2012.

5. Akiri G, Sabo E, Dafni H, Vadasz Z, Kartvelishvily Y, Gan N, Kessler O, Cohen T, Resnick M, Neeman M and Neufeld G: Lysyl oxidase-related protein-1 promotes tumor fibrosis and tumor progression in vivo. Cancer Res 63: 1657-1666, 2003.

6. Payne SL, Hendrix MJ and Kirschmann DA: Paradoxical roles for lysyl oxidases in cancer-a prospect. J Cell Biochem 101: 1338-1354, 2007.

7. Hayashi K, Fong KS, Mercier F, Boyd CD, Csiszar K and Hayashi M: Comparative immunocytochemical localization of lysyl oxidase (LOX) and the lysyl oxidase-like (LOXL) proteins: Changes in the expression of LOXL during development and growth of mouse tissues. J Mol Histol 35: 845-855, 2004.

8. Peinado H, Moreno-Bueno G, Hardisson D, Pérez-Gómez E, Santos V, Mendiola M, de Diego JI, Nistal M, Quintanilla M, Portillo F and Cano A: Lysyl oxidase-like 2 as a new poor prognosis marker of squamous cell carcinomas. Cancer Res 68: 4541-4550, 2008.

9. Li TY, Xu LY, Wu ZY, Liao LD, Shen JH, Xu XE, Du ZP, Zhao Q and Li EM: Reduced nuclear and ectopic cytoplasmic expression of lysyl oxidase-like 2 is associated with lymph node metastasis and poor prognosis in esophageal squamous cell carcinoma. Hum Pathol 43: 1068-1076, 2012.

10. Macartney-Coxson DP, Hood KA, Shi HJ, Ward T, Wiles A, O'Connor R, Hall DA, Lea RA, Royds JA, Stubbs RS and Rooker S: Metastaticsusceptibility locus, an $8 \mathrm{p}$ hot-spot for tumour progression disrupted in colorectal liver metastases: 13 candidate genes examined at the DNA, mRNA and protein level. BMC Cancer 8: 187, 2008.

11. Offenberg H, Brünner N, Mansilla F, Orntoft Torben F and Birkenkamp-Demtroder K: TIMP-1 expression in human colorectal cancer is associated with TGF-B1, LOXL2, INHBA1, TNF-AIP6 and TIMP-2 transcript profiles. Mol Oncol 2: 233-240, 2008.

12. Peng L, Ran YL, Hu H, Yu L, Liu Q, Zhou Z, Sun YM, Sun LC, Pan J, Sun LX, et al: Secreted LOXL2 is a novel therapeutic target that promotes gastric cancer metastasis via the Src/FAK pathway. Carcinogenesis 30: 1660-1669, 2009. 
13. Sano M, Aoyagi K, Takahashi H, Kawamura T, Mabuchi T, Igaki H, Tachimori Y, Kato H, Ochiai A, Honda H, et al: Forkhead box A1 transcriptional pathway in KRT7-expressing esophageal squamous cell carcinomas with extensive lymph node metastasis. Int J Oncol 36: 321-330, 2010.

14. Brekhman V and Neufeld G: A novel asymmetric 3D in-vitro assay for the study of tumor cell invasion. BMC Cancer 9: 415, 2009.

15. Wong CC, Tse AP, Huang YP, Zhu YT, Chiu DK, Lai RK, Au SL, Kai AK, Lee JM, Wei LL, et al: Lysyl oxidase-like 2 is critical to tumor microenvironment and metastatic niche formation in hepatocellular carcinoma. Hepatology 60: 1645-1658, 2014.

16. Ferrandon S, Saultier P, Carras J, Battiston-Montagne $P$, Alphonse G, Beuve M, Malleval C, Honnorat J, Slatter T, Hung N, et al: Telomere profiling: Toward glioblastoma personalized medicine. Mol Neurobiol 47: 64-76, 2013.

17. Hahn WC, Dessain SK, Brooks MW, King JE, Elenbaas B, Sabatini DM, DeCaprio JA and Weinberg RA: Enumeration of the simian virus 40 early region elements necessary for human cell transformation. Mol Cell Biol 22: 2111-2123, 2002.

18. Song S, Zhou J, He S, Zhu D, Zhang Z, Zhao H, Wang Y and Li D: Expression levels of microRNA-375 in pancreatic cancer. Biomed Rep 1: 393-398, 2013.

19. Zheng Y, Wang DD, Wang W, Pan K, Huang CY, Li YF, Wang QJ, Yuan SQ, Jiang SS, Qiu HB, et al: Reduced expression of uroplakin $1 \mathrm{~A}$ is associated with the poor prognosis of gastric adenocarcinoma patients. PLoS One 9: e93073, 2014

20. Li TY, Xu LY, Wu ZY, Liao LD, Shen JH, Xu XE, Du ZP, Zhao Q and Li EM: Reduced nuclear and ectopic cytoplasmic expression of lysyl oxidase-like 2 is associated with lymph node metastasis and poor prognosis in esophageal squamous cell carcinoma. Hum Pathol 43: 1068-1076, 2012.
21. Erler JT, Bennewith KL, Nicolau M, Dornhöfer N, Kong C, Le QT, Chi JT, Jeffrey SS and Giaccia AJ: Lysyl oxidase is essential for hypoxia-induced metastasis. Nature 440: 1222-1226, 2006.

22. Barry-Hamilton V, Spangler R, Marshall D, McCauley S, Rodriguez HM, Oyasu M, Mikels A, Vaysberg M, Ghermazien H, Wai C, et al: Allosteric inhibition of lysyl oxidase-like-2 impedes the development of a pathologic microenvironment. Nat Med 16: 1009-1017, 2010

23. Barker HE, Chang J, Cox TR, Lang G, Bird D, Nicolau M, Evans HR, Gartland A and Erler JT: LOXL2-mediated matrix remodeling in metastasis and mammary gland involution. Cancer Res 71: 1561-1572, 2011.

24. Barker HE, Cox TR and Erler JT: The rationale for targeting the LOX family in cancer. Nat Rev Cancer 12: 540-552, 2012

25. Peinado H, Del Carmen Iglesias-de la Cruz M, Olmeda D, Csiszar K, Fong KS, Vega S, Nieto MA, Cano A and Portillo F: A molecular role for lysyl oxidase-like 2 enzyme in snail regulation and tumor progression. EMBO J 24: 3446-3458, 2005.

26. Bhowmick NA, Neilson EG and Moses HL: Stromal fibroblasts in cancer initiation and progression. Nature 432: 332-337, 2004.

27. Mahadevan D and Von Hoff DD: Tumor-stroma interactions in pancreatic ductal adenocarcinoma. Mol Cancer Ther 6: 1186-1197, 2007.

28. Radisky D, Hagios C and Bissell MJ: Tumors are unique organs defined by abnormal signaling and context. Semin Cancer Biol 11: 87-95, 2001.

29. Tlsty TD and Coussens LM: Tumor stroma and regulation of cancer development. Annu Rev Pathol 1: 119-150, 2006. 